Check for updates

Cite this: J. Mater. Chem. A, 2019, 7, 2981

Received 7th November 2018 Accepted 25th January 2019

DOI: $10.1039 / c 8 t a 10711 d$

rsc.li/materials-a

\section{Nanofibrillated cellulose composites and wood derived scaffolds for functional materials}

\begin{abstract}
Tobias Keplinger, (D) $\uparrow^{\mathrm{ab}}$ Xiaoqing Wang (D) $\uparrow^{\mathrm{c}}$ and Ingo Burgert (D) *ab
As an alternative to the production of nanofibrillated cellulose based composites (NFC) in bottom-up processes the functionalization of wood or cellulose scaffold materials in a top-down approach has attracted increasing attention in recent years. Here we compare both concepts regarding mechanical properties, electric and magnetic properties as well as filtration and adsorption properties for oil/water separation and heavy metal remediation. Depending on the targeted properties, both the bottom-up and the top-down approach show specific advantages and limitations in processing and performance. The comparison shows that the use of wood and wood derived cellulose scaffolds is a very promising alternative to the assembly of NFC for developing green and scalable functional materials.
\end{abstract}

\section{Introduction}

The fabrication of functional materials in bottom-up approaches using cellulose nanofibrils (NFC) has attracted increasing attention over the last 20 years. The large surface area and the high amount of reaction sites make NFC a very attractive renewable raw material. ${ }^{1}$ However, there are limiting factors for a wider utilization such as energy-intense disassembly processes and challenges to achieve a beneficial parallel alignment of NFC in the composite. Recently, there has been great progress regarding cellulose fibril alignment by a sophisticated microfluidic system, resulting in high performance macroscale fibres, ${ }^{2}$ but the fabrication of NFC composites with high fibre directionality remains challenging. An emerging manufacturing and functionalization alternative is based on a top-down approach, which either utilizes the hierarchical structure of native wood or comprises a full or partial delignification to fabricate cellulose scaffolds that retain the original fibre directionality and structural integrity. ${ }^{3-6}$ Wood itself or these cellulose scaffolds can be functionalized or densified in subsequent treatment steps. Here, we intend to review properties of materials based on assembled cellulose fibrils and on cellulose scaffolds or wood. The comparison is a first indicator for which properties or functions a top-down or bottom-up approach might be more beneficial. We have selected three categories of properties with high application relevance, namely mechanical properties in terms of strength and stiffness,

${ }^{a}$ ETH Zurich, Wood Materials Science, Institute for Building Materials, 8093 Zurich, Switzerland. E-mail: iburgert@ethz.ch

${ }^{b}$ Empa - Swiss Federal Laboratories for Material Testing and Research, Applied Wood Research Laboratory, Dübendorf, Switzerland

${ }^{c}$ Chinese Academy of Forestry, Research Institute of Wood Industry, 100091 Beijing, China

$\dagger$ Authors contributed equally. electric and magnetic properties as well as filtration and adsorption properties for oil/water separation and heavy metal remediation.

\section{Mechanical properties}

Nano- and microfibrillated cellulose can be prepared by different methods from a large variety of natural resources (Fig. 1) 7 to be used as reinforcement in combination with a multitude of natural or synthetic matrices to produce polymer composites. ${ }^{8,9}$ Dufresne and coworkers were the first to show the reinforcing effect of NFC in cellulose-starch composites. ${ }^{10}$ In the following various combinations with arabinoxylan,
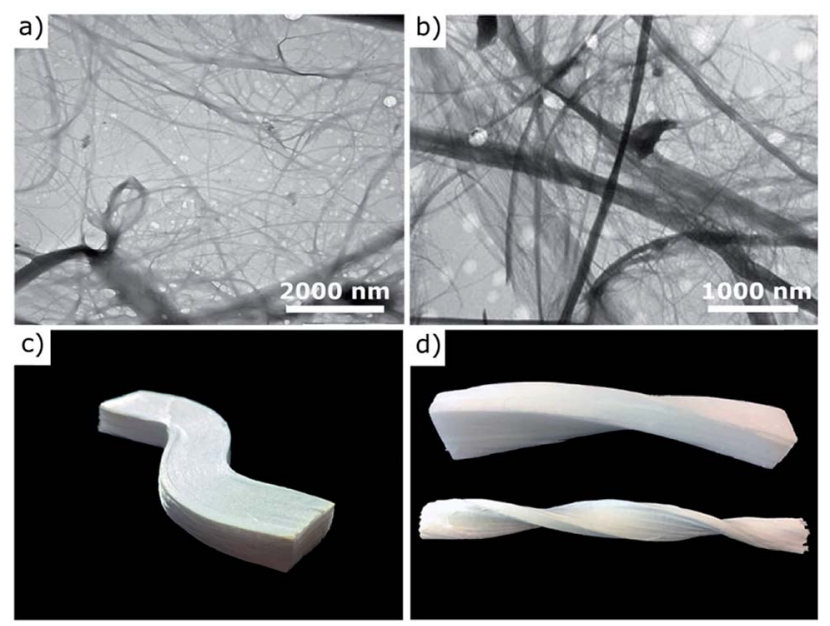

Fig. 1 Transmission electron microscope (TEM) images of cellulose nanofibers of (a) kenaf ${ }^{25}$ and (b) rubberwood ${ }^{26}$ and (c), (d) images of shaped wood-based cellulose scaffolds. ${ }^{3}$ Reprinted by permission from Springer Nature; ${ }^{25,26}$ reprinted with permission from American Chemical Society. ${ }^{3}$ 
carboxymethyl cellulose, hydroxypropyl cellulose, regenerated cellulose, galactoglucomannan, xyloglucan, chitosan, or adhesives peptides have been tested. ${ }^{\mathbf{1 1 - 1 5}}$ Nano- and microfibrillated cellulose composites with a phenol-formaldehyde- or melamine formaldehyde resin matrix were produced by Nakagaito and Yano $^{\mathbf{1 6}}$ and Henriksson and Berglund, ${ }^{\mathbf{1 7}}$ respectively.

In recent years, several wood delignification approaches have been followed to fabricate cellulose based materials that benefit from the hierarchical structure of the cellulose scaffolds. A structure-preserving delignification protocol was first introduced as a preparation method for light microscopy studies. ${ }^{18}$ Later it was shown that delignification allows for the preparation of wood templated ceramics down to the nanoscale of the wood cell wall. ${ }^{19}$ Yano and coworkers densified partly delignified wood samples together with a PF-resin to produce extremely strong and stiff densified composites., ${ }^{\mathbf{6} 20}$ Song and coworkers utilized the bonding capacity of lignin and achieved very high strength, stiffness and toughness values for partly delignified cellulose composites. ${ }^{5}$ Fully delignified cellulose scaffolds (Fig. 1) were produced by Frey et al., which were then densified by a combined action of compression and shear. ${ }^{3}$ Various delignification approaches also facilitated the fabrication of wood sponges ${ }^{21}$ or transparent wood..$^{22,23}$ These scaffolds were filled for instance with PMMA to add a polymer with a similar refractive index compared to cellulose, resulting in transparent polymer composites. ${ }^{24}$

For the comparison of the mechanical properties of polymer composites made of nano- and microfibrillated cellulose on the one side and wood/cellulose scaffolds on the other, we have used the very comprehensive review article by Lee and coworkers as a basis. ${ }^{9}$ In this article the reinforcing ability of NFC in a multitude of polymer nanocomposites has been compared. This is compiled with the mechanical properties of a selected wood species and a small number of cellulose scaffold based composites displaying strength against stiffness (Fig. 2).

The light blue-colored region reflects the region of strength and stiffness values of NFC composites. The vast majority possesses values around $80 \mathrm{MPa}$ strength and an elastic modulus around $4 \mathrm{GPa} .{ }^{9}$ Only NFC composites with a very high fibre volume fraction reach exceptional strength values of up to $360 \mathrm{MPa}$ and elastic moduli around $19 \mathrm{GPa} .{ }^{\mathbf{1 6}}$

Natural wood (here we show Japanese cedar according to the cited reference) with a comparably low density of $\left(\sim 340 \mathrm{~kg} \mathrm{~m}^{-3}\right)$ possesses a tensile strength around $80 \mathrm{MPa}$ and an elastic modulus around $10 \mathrm{GPa}$, while its strong densification $\left(1200 \mathrm{~kg} \mathrm{~m}^{-3}\right)$ results in an increase in fibre volume fraction and an elastic modulus of $30 \mathrm{GPa}$ and a bending strength of $300 \mathrm{MPa} .{ }^{27}$ In their study on transparent wood, Li and coworkers conducted mechanical tests on the transparent cellulose scaffold-PMMA composites. For a cellulose volume fraction of 5\%, an elastic modulus of $2 \mathrm{GPa}$ and a tensile strength of $40 \mathrm{MPa}$ were measured. ${ }^{22}$ Zhu et al. measured similar values for their transparent wood samples, but the volume fraction of cellulose was not provided in that article. ${ }^{23}$ Upon compressing transparent wood, the cellulose volume fraction was increased to
19\% and tensile strength (90 MPa) and elastic modulus (3.6 GPa) were improved. ${ }^{22}$

With the objective to optimize the mechanical performance of cellulose scaffold based composites, Yano performed a very systematic study to produce high-strength materials. In a preliminary assessment he conducted sound velocity tests on wood specimens to identify those with the highest elastic modulus. After partial delignification and PF resin impregnation the specimens were strongly compressed to reach density values of $1400 \mathrm{~kg} \mathrm{~m}^{-3}$, which led to a bending strength of $670 \mathrm{MPa}$ and an elastic modulus of $62 \mathrm{GPa}$ (green star). ${ }^{6}$ Other cellulose-PF resin composites without preselection of specimens reached lower strength and stiffness values. ${ }^{20}$ Recently, Song et al. compressed partly delignified cellulose scaffolds at $100{ }^{\circ} \mathrm{C}$ activating the binding capacities of lignin. For samples with a weight loss of $45 \%$ (partial degradation of hemicelluloses and lignin) the highest mechanical properties were measured. These samples had a density of $1300 \mathrm{~kg} \mathrm{~m}^{-3}$ and possessed a strength of almost $600 \mathrm{MPa}$ and an elastic modulus of $51 \mathrm{GPa}$ (red star). ${ }^{5}$ Frey and coworkers reached an elastic modulus of $35 \mathrm{GPa}$ and a tensile strength of $270 \mathrm{MPa}$ when testing densified cellulose scaffolds without adding any matrix. This data point (blue star) is below the dashed line in Fig. 2, which acts a visual guideline for comparison of wood and the different cellulose scaffold composites. A possible explanation is that in particular the strength is affected by the absence of a matrix. The comparison in Fig. 2 clearly shows that much stronger cellulose composites can be obtained, when densified cellulose scaffolds are utilized compared to NFC/MFC composites. For a better understanding of the underlying structure-property relationships, one needs to consider the large variety of parameters, like cellulose volume fraction, fibril geometry, cellulose source or wood species, degree of delignification and hemicellulose removal, cellulose orientation, polymer matrix, porosity, or interfacial properties of the fabricated composites. The mechanical properties of nano- and microfibrillated cellulose composites depend in particular on the applied preparation methods to produce the cellulose nanofibrils. ${ }^{7}$ This was for instance shown in a study by Fukuzumi and coworkers, who studied the influence of the length of TEMPO oxidized nanocellulose fibrils on the mechanical properties of different NFC composites. The aspect ratios of the nanofibrils were varied due to different mechanical disintegration conditions. The nanofibrils had different lengths $(200,680,1100 \mathrm{~nm})$ but the same width of about $4 \mathrm{~nm}$. Microtensile tests revealed an increase of tensile strength and an increased elongation at break with increasing nanofibril length. ${ }^{28}$

Here we would like to restrict ourselves to a more detailed comparison of two parameters of crucial relevance for which a sufficient amount of data is available. A parameter with strong impact on the mechanical properties is the relative cellulose volume fraction. When comparing the different NFC polymer nanocomposites from literature, Lee and coworkers could show a good correlation with strength and elastic modulus. While composites with a NFC volume fraction of $10 \%$ reached strength values of max. $100 \mathrm{MPa}$ and elastic moduli values of max. $5 \mathrm{GPa}$, composites with a NFC volume fraction above $80 \%$ 


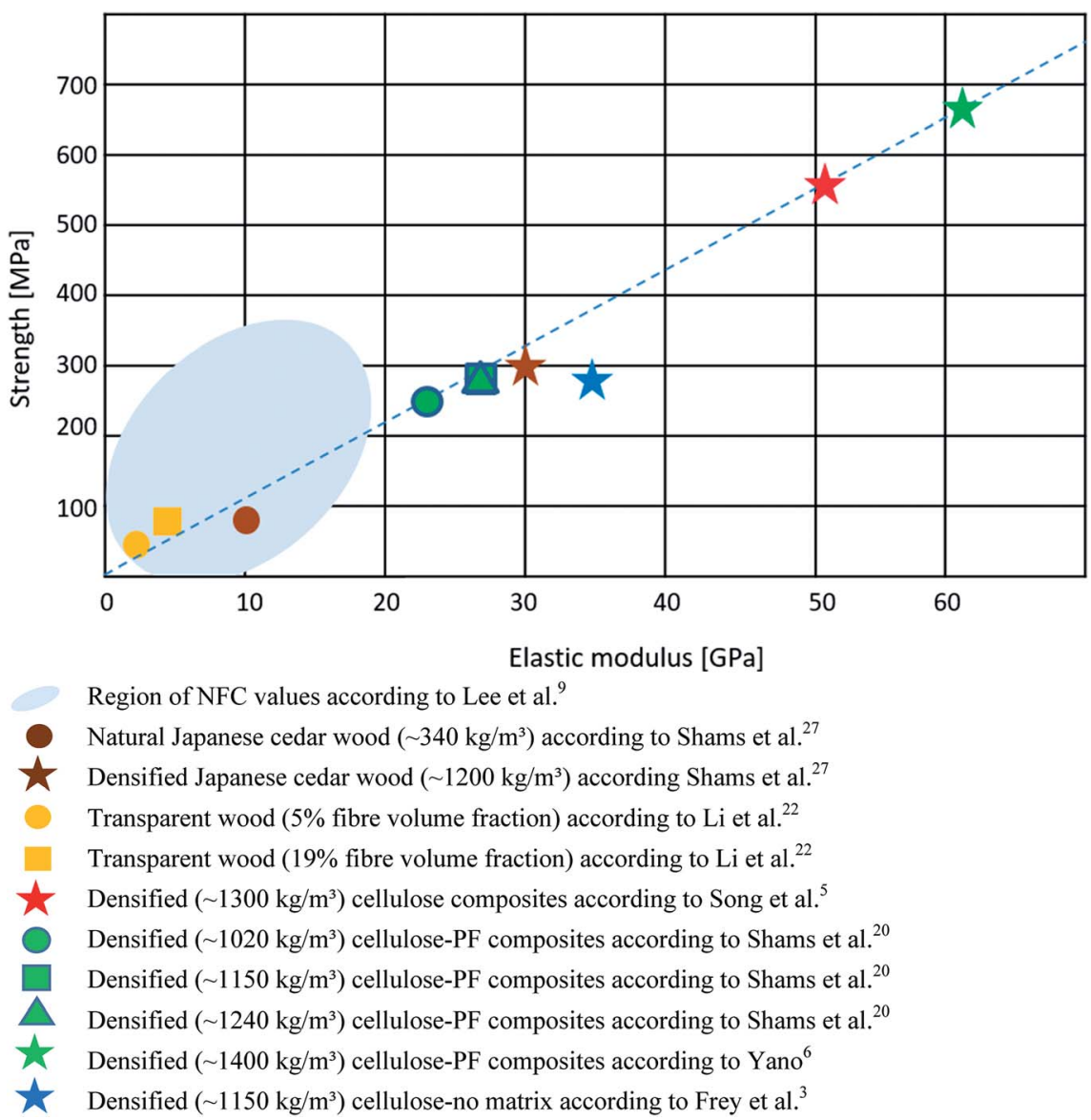

Fig. 2 Elastic modulus against strength of NFC/MFC composites, wood (natural and densified) and cellulose composites utilizing the hierarchical scaffold of wood. Note that mechanical properties were either measured in tension or bending. Dashed line acts a visual guideline for comparison of wood and the different cellulose scaffold composites.

possessed a strength and an elastic modulus around 3 times higher. ${ }^{9}$ The same trend can also be observed for wood and the cellulose scaffold composites. The direct comparison of transparent wood studied by Li and coworkers shows that an increase of the volume fraction of the cellulose scaffold from $5 \%$ to $19 \%$ doubles the strength and elastic modulus values..$^{22}$ However, density as a single parameter is not useful for a general comparison of composites with different matrices and degrees of densification as it is not necessarily correlated with cellulose volume fraction. For instance, transparent wood has a high density, but comparably low strength and stiffness, because PMMA, which has the largest volume fraction in these composites, possesses a density of $1150 \mathrm{~kg} \mathrm{~m}^{-3} .^{20,22}$

Another parameter, with a strong impact on mechanical performance is the cellulose orientation. While NFC composites often have a random distribution of cellulose fibrils or less pronounced anisotropy, the fibre directionality of wood is retained in the cellulose scaffold composites resulting in a strong anisotropy with a high elastic modulus in the longitudinal direction. However, Fig. 2 clearly shows that the influence of cellulose orientation cannot be evaluated without considering the additional influence of cellulose volume fraction. The transparent wood samples have a strong fibre directionality and anisotropy but their values of strength and elastic modulus are well in the region of NFC composites, which shows that the impact of fibre directionality scales with fibre volume content. This becomes very obvious, when comparing the properties of MFC-PF resin composites and cellulose scaffold$\mathrm{PF}$ resin composites fabricated by the research group of Yano ${ }^{6,16,20}$ For high MFC volume contents above $80 \%$, densities between $1400 \mathrm{~kg} \mathrm{~m}^{-3}$ and $1500 \mathrm{~kg} \mathrm{~m}^{-3}$ were reached, which allows for direct comparison with the properties of the cellulose scaffold-PF resin composites compressed to a density of $\sim 1400$ $\mathrm{kg} \mathrm{m}^{-3}$. The later exceed the MFC composites by a factor of 3 in stiffness and by a factor of 2 in strength. Hence, for densified high-strength and high-stiffness cellulose composites a utilization of the fibre directionality of wood is highly beneficial and an energy-intense disassembly may be even counter-intuitive. Although the high stiffness of approx. 65 GPa for a nanocellulose fibril ${ }^{29}$ is often emphasized in NFC composite studies, the commonly applied assembly processes for composites are not yet eligible to utilize this performance.

For the high-strength cellulose scaffold composites there seems to be a good correlation between densification (cellulose volume fraction) and elastic modulus. Based on our comparison of available strength and stiffness data points, assumptions on an additional "cellulose fibrillation effect" for a superior mechanical performance of cellulose scaffolds cannot be 
confirmed. Moreover, it seems unlikely that a cellulose fibrillation can be caused by a two-step process of (partial) delignification and densification.

\section{Electrically conductive cellulose materials and wood}

The broad range of available cellulose morphologies allows for developing materials with manifold electrical properties, including materials with high electrical conductivity, ON-OFF electrical, optical switching or electrochemical redox properties. They are used as sensors, for energy harvesting and electromechanics, in the biomedical field or in catalysis. ${ }^{30,31}$ Here, we specifically focus on synthesis routes which maintain the native structure and composition of the cellulose or wood materials. For a detailed review on using carbonisation of biomass to obtain conductive cellulose materials the reader is referred to a recent review by Correa et al. ${ }^{32}$

Three main fabrication routes are distinguished for the development of electrically conductive cellulose materials: the cellulosic material can either be blended, coated or doped with the electro-conductive material. Electrically conductive constituents comprise metal ions and oxides, inorganic particles, carbon nanotubes, graphene oxide or conductive polymers. ${ }^{30,33}$

Conductive polymers, first developed in the 1970s, represent highly conjugated polymers with spatially extended $\pi$-bonding, which are built up of basic structures such as polyacetylene, polypyrrole, polyfuran and polyaniline. ${ }^{34}$ In order to obtain electrical conductive cellulose composites, films were, for instance, cast from aqueous slurries consisting of carboxymethyl cellulose and polypyrrole particles or NFC aerogels were simply dipped in polyaniline-dodecylbenzene sulphonate solution in toluene to coat the aerogel..$^{35,36}$ Further, polypyrrole and polyaniline were in situ polymerized in cellulose pulp suspensions followed by the formation of conduction paper sheets. ${ }^{37,38}$ It is important to note that for the polymerization of conductive polymers (e.g. pyrrole) typically oxidants at very low $\mathrm{pH}$ values are used. Thus the potential influence of the acidic environment on the cellulose properties must be considered. ${ }^{33}$

In addition to conductive polymers carbon nanotubes and graphene are frequently used for the fabrication of cellulose composites. Since their discovery in 1991 carbon nanotubes are used in many applications due to their unique properties in terms of mechanical, thermal and electronic properties. Two different types of carbon nanotubes are distinguished: single walled carbon nanotubes (SWCNTs) characterized by a single layer of graphene in a cylindrical tube shape and multi-walled carbon nanotubes (MWCNTs) consisting of multiple graphene layers. ${ }^{39}$ Cellulose nanofibers were mixed with SWCNTs to obtain composite films with relatively high conductivity of $3 \mathrm{~S} \mathrm{~cm}^{-1}$ (ref. 40) and MWNTs were dispersed in a cellulose triacetate solution and composite films were prepared with potential applications in electromagnetic shielding. ${ }^{41}$ Reasonable conductivity of $0.1 \mathrm{~S} \mathrm{~cm}^{-1}$ was also obtained by loading with $10 \%$ graphene oxide. ${ }^{42}$ Its high mechanical strength and conductivity makes graphene oxide an ideal candidate to be used in composites and graphene oxide cellulose composites are for instance applied as flexible electrodes in supercapacitors as they keep their conductivity even after multiple bending events. ${ }^{30,33,43}$

A third option for the fabrication of conductive cellulose composites is based on the incorporation of an inorganic phase. Cellulose composites loaded with copper, incorporated by electrolysis plating ${ }^{44}$ or tin oxide formed on cellulose via a sol gel process ${ }^{\mathbf{4 5}}$ were prepared. Alternatively, conductive paper was obtained by atomic layer deposition of $\mathrm{ZnO}$ or by the in situ synthesis of $\mathrm{TiO}_{2}$ nanoparticles within the cellulose matrix. ${ }^{\mathbf{4 6}}$ Especially $\mathrm{TiO}_{2}$-cellulose composites are of great interest due to their photocatalytic activity to be used for example in waste water treatments. ${ }^{47}$ Table 1 provides an overview of strategies for the development of cellulose based conductive composites and the conductivities that can be achieved.

In contrast to numerous examples of electrically conductive cellulose composites only a very limited amount of publications has dealt with the development of conductive wood. Trey et al. reported on the functionalization of entire wood veneers by conductive polymers. The veneers were impregnated with aniline monomer solution and in a second step in situ polymerized..$^{53}$ Despite the limited weight gain of below $10 \%$ a semiconductive behaviour of the veneers was reached. A similar approach was followed by Lv et $a .^{54}$ to fabricate a flexible supercapacitor based on wood. Thin wood slices were first impregnated with pyrrole monomer followed by in situ polymerization. The polypyrrole-modified wood electrodes reveal good specific capacitance and cyclic stability. An alternative route to construct a wood based supercapacitor was demonstrated by $\mathrm{Hu}$ and co-workers, using a wood-carbonization route..$^{55}$

A main advantage of using wood as a template is its inherent fibrous architecture, resulting in anisotropic properties. Rather recently this wood inherent anisotropy was used for the development of composites with highly anisotropic electrical and thermal conductivity. Wood was filled with $\mathrm{Sn}-\mathrm{Bi}$ alloy in its liquid state and then solidified at room temperature. In fibre/ vessel direction high electrical conductivity is reached due to the continuous electron pathway whereas perpendicular to fibre direction the lack of contact between the channels limits the conductivity. The obtained samples reveal an electrical anisotropic ratio of up to $10^{11} .^{56}$ Electrical anisotropic conductivity of wood samples was also reported by Guo et al. Copper nanowires were formed on wood surfaces and the electrical properties are determined by the surface topography of wood resulting in a highly anisotropic conductivity. ${ }^{57}$ Considering the limited publications on this topic, additional work especially targeting the development of highly conductive wood and cellulose scaffolds while retaining the porous lightweight structure would be of high interest for various applications.

\section{Magnetic cellulose materials and wood}

Magnetic cellulosic materials of different morphologies have been developed within recent years ranging from cellulose fibres, ${ }^{58,59}$ lignocellulosic pulp, ${ }^{60-62}$ nano-fibrillated cellulose 
Table 1 Strategies for the development of cellulose based conductive composites

\begin{tabular}{|c|c|c|c|c|}
\hline Conductive material & Process & Conductivity & Applications & Literature \\
\hline $\begin{array}{l}\text { Conductive polymers (PPy; } \\
\text { PANI; PA; PPs; PP; PTh;... }\end{array}$ & $\begin{array}{l}\text { Coating (e.g. fibers), in situ } \\
\text { polymerization; casting of } \\
\text { dispersions; layer by layer } \\
\text { coating }\end{array}$ & $10^{-5}-10^{2} \mathrm{~S} \mathrm{~cm}^{-1}$ & $\begin{array}{l}\text { Organic electronics; } \\
\text { biosensors; } \\
\text { electromechanics }\end{array}$ & $48-50$ \\
\hline $\begin{array}{l}\text { Carbon nanotubes, } \\
\text { graphene oxide }\end{array}$ & $\begin{array}{l}\text { Blending in cellulose matrix; } \\
\text { solvent casting after } \\
\text { blending; electrospinning, } \\
\text { 3D-printing }\end{array}$ & $10^{-4}-10^{2} \mathrm{~S} \mathrm{~cm}^{-1}$ & $\begin{array}{l}\text { Energy storage; wearable } \\
\text { electronics; flexible } \\
\text { supercapacitors and } \\
\text { electrodes }\end{array}$ & 43,50 and 51 \\
\hline $\begin{array}{l}\text { Inorganic nanoparticles } \\
\left(\mathrm{SnO}_{2} ; \mathrm{TiO}_{2} ; \mathrm{Au} ; \mathrm{Ag} ; \mathrm{Cu} ; \mathrm{ZnO}\right)\end{array}$ & $\begin{array}{l}\text { Liquid phase deposition; } \\
\text { atomic layer deposition; } \\
\text { molding after mixing }\end{array}$ & $10^{-6}-10^{3} \mathrm{~S} \mathrm{~cm}^{-1}$ & $\begin{array}{l}\text { Chemical sensing; } \\
\text { biosensing; photocatalysis }\end{array}$ & $44,46,47$ and 52 \\
\hline
\end{tabular}

(NFC),$^{63}$ over cellulose aerogels ${ }^{64}$ to cellulose nanocrystals ${ }^{65}$ with potential applications in biomedicine, textronics, security papermaking, magnetic membranes for purification, filtration, magneto-responsive actuators and flexible data storage. They have in common that they are mainly obtained by the incorporation of either iron oxides, ${ }^{66}$ nickel $^{67}$ or cobalt ferrites. ${ }^{64}$ In classical approaches the inorganic particles are first synthesized and then mixed with the corresponding cellulosic material. ${ }^{68,69}$ Nevertheless this approach is hindered when high nanoparticle loadings for high functionality are targeted, as the nanoparticles tend to agglomerate at high concentrations which influences the processing and compromises the macroscopic properties. ${ }^{70}$ This is of particular relevance for magnetic nanoparticles as they exhibit inter-particle dipolar forces. ${ }^{71}$ Alternatively, cellulosic materials can be used as template for the in situ growth of magnetic nanoparticles methods including for example the classical co-precipitation of ferrous and ferric salts in aqueous solutions using alkaline solutions. ${ }^{72}$ Depending on the process and the process conditions different structures of iron oxide such as hematite, maghemite and magnetite are formed. Among these three structures, magnetite exhibits the strongest magnetism. Under ambient conditions hematite and maghemite are preferentially formed, whereas an oxygen free ammonia gas atmosphere as proposed by Katepetch et al. fosters the exclusive formation of magnetite. ${ }^{73}$

Olsson et al. ${ }^{64}$ developed magnetic cellulose aerogels by using freeze dried bacterial cellulose, which was modified by in situ growing of ferromagnetic cobalt ferrite. The obtained aerogels exhibit high flexibility, high porosity and surface area with potential applications in microfluidics or electronic actuators. For the ease of processing it would be beneficial to have the cellulose material (e.g. cellulose fibrils) and the magnetic nanoparticles in liquid form. Thus Galland et al. ${ }^{74}$ proposed a single step process based on the in situ precipitation of metal ions on cellulose nanofibrils to obtain a magnetic colloidal suspension respectively hydrogel with a high content of the inorganic phase (more than $50 \mathrm{wt} \%$ ). The hydrogel can be then further liquid-processed into different shapes by molding or filtration at room temperature. By that it was possible to fabricate ultrathin magnetic membranes with sufficient mechanical stability due to the interpenetrating network of the cellulose nanofibrils but also sufficient functionality. It was shown that the fabricated membrane is applicable in loudspeaker applications.

\section{co-precipitation}

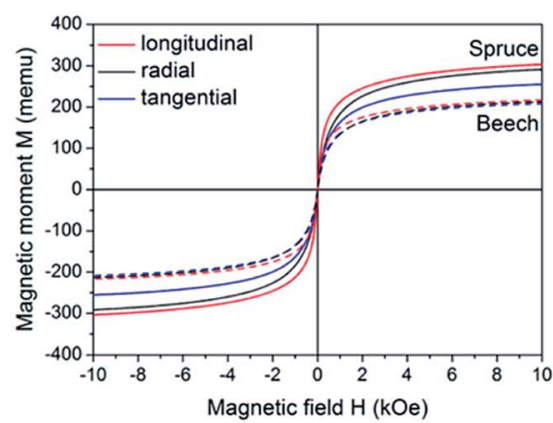

microwave-assisted magnetization

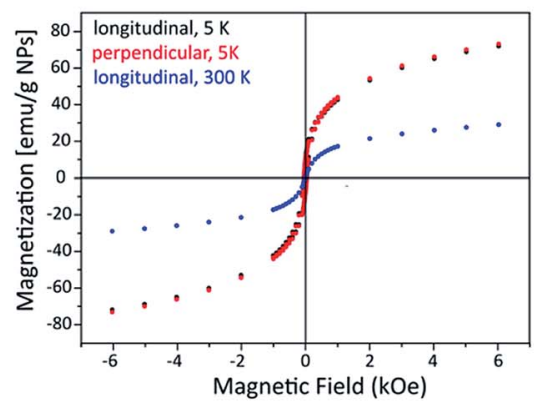

Fig. 3 Magnetic characterization of wood synthesized by two different methods: co-precipitation of ferric and ferrous salts in aqueous media (left) and the microwave assisted formation of metal oxide nanoparticles via a non-aqueous thermal decomposition process (right). Due to the difference in distribution of magnetic particles a different magnetic behaviour is obtained. Whereas samples, prepared by co-precipitation, reveal a clear anisotropic behaviour samples prepared with the microwave process show now anisotropy on the microscale but on the macroscopic scale. Reprinted with permission from the American Chemical Society; ${ }^{83}$ reproduced by permission of The Royal Society of Chemistry. ${ }^{84}$ 
An emerging field of application of magnetically modified cellulosic materials is the development of bio-based magnetic cellulose adsorbents for filtration purposes. Various different methods for the remediation of heavy metals or dyes have been developed comprising chemical precipitation, membrane filtration, flotation or electrochemical treatment. ${ }^{75}$ However, most of these approaches engage disadvantages such as high costs, complex manufacturing and operation. Alternatively, bioadsorbents are very promising due to their ready availability, low cost, biodegradability and biocompatibility. ${ }^{76}$ Their main disadvantage includes difficulties to separate the bio-adsorbent and the effluent - for that filtration or high speed centrifugation is normally needed. By magnetizing the cellulosic bio-adsorbent this limitation can be simply overcome as the adsorbent can be separated from the effluent by applying an external magnetic field. ${ }^{77}$

Early works of Oka et al. report on the simple pressure impregnation of wood and wood materials with aqueous magnetite particle dispersions proposing applications of the magnetized wood materials in electromagnetic shielding, actuation or induction heating..$^{78-80}$

The potential of magnetic wood as induction heating material was recently investigated by Gan and coworkers, by measuring a temperature rise of the magnetic wood from $\sim 20{ }^{\circ} \mathrm{C}$ to $\sim 70{ }^{\circ} \mathrm{C}$ in $10 \mathrm{~min}$ at a low frequency magnetic field. In addition the magnetic wood acts as a thermal insulator due to the low thermal conductivity. ${ }^{81}$ In a further study, they showed the improved UV resistance and dimensional stability of magnetic wood composites. ${ }^{82}$

A more detailed study on magnetized wood, in terms of distribution, penetration depth and colloidal characteristics, was reported by Merk et al. ${ }^{83}$ Iron oxide magnetite and maghemite were in situ synthesized within the bulk wood structure by a co-precipitation process of ferric and ferrous salts in aqueous media with alkaline solutions. Interestingly, the magnetized samples clearly reveal a direction dependent magnetic behaviour respectively a pronounced anisotropic magnetic behaviour which is correlated to the internal fibrous wood structure and the predominant deposition of ferrites along the inner cell walls. The exact spatial distribution was characterized by confocal Raman spectroscopy imaging and electron microscopy. Segmehl et al. introduced a different approach for the magnetization in order to avoid material deposition in the lumina. For that, a microwave assisted formation of metal oxide nanoparticles via a non-aqueous thermal decomposition process was used. The even temperature profile due to microwave heating and the wood inherent polar hydroxyl groups acting as nucleation sites provide a homogeneous particle distribution and final functionality. In contrast to previously described co-precipitation a relatively uniform deposition of nanoparticles in the cell wall and compound middle lamella proven by Raman spectroscopy was obtained. As a result of the homogeneous distribution no anisotropy on the microscopic level was obtained, whereas on the macroscopic level an anisotropic behaviour is still detected (Fig. 3). ${ }^{84}$

\section{Cellulose nanomaterials and wood for oil/water separation and heavy metals remediation}

The heavy discharge of oily wastewater from industries and our daily life, and frequent oil spill accidents occurring during oil exploitation and transportation have aroused considerable global concerns with regard to their harmful impacts on the environment. ${ }^{85,86}$ The traditional oil/water separation methods including in situ burning, mechanical extraction, chemical treatments, electrochemical processes, and bioremediation suffer from low separation efficiencies, secondary pollutions, and high costs. ${ }^{87,88}$ Alternatively, a separation based on adsorption and filtration is generally more promising due to its relatively low cost, easy operation and high efficiency. In particular, three-dimensional (3D) porous materials (aerogels or sponges) derived from synthetic polymers, ${ }^{89,90}$ carbon nanotubes, ${ }^{91,92}$ and graphene ${ }^{93,94}$ have been extensively explored. However, the complicated assembly processes, high cost and poor degradability of these materials hinder their practical utilization. In this context, there are growing interests in utilizing sustainable cellulose materials for developing environmentally friendly oil absorbents or filtration membranes.95,96 Herein, we summarize the advance of nanofibrillated cellulose (NFC)-derived aerogels and wood-based scaffold materials for oil/water separation.

Highly porous NFC aerogels with entangled nanofibrils can be prepared via freeze-drying or supercritical drying techniques, which allow for retaining the porous structure during solvent removal. ${ }^{97}$ Recently, cellulose aerogels derived from NFCs have attracted a lot of attention due to their fascinating properties, such as renewability, low density, high porosity, large specific surface area, flexibility, and biodegradability, ${ }^{98,99}$ which make them promising candidates for sustainable absorbent materials. However, due to the presence of abundant hydroxyl groups, the native NFC aerogels are intrinsically hydrophilic, resulting in poor oil/water selectivity. The hydrophilic nature of the aerogels also provokes structural collapse upon contact with water, making them unsuitable for direct application in oil/ water separation. Therefore, they have to be chemically modified to render the cellulose fibrils hydrophobic. In general, there are mainly two pathways to tune the surface wettability of the cellulose aerogels, i.e., modification of the aerogels or modification of the NFC dispersions prior to drying.

An ideal modification of the cellulose in the aerogel is expected to retain the highly porous structure as much as possible. In this regard, chemical vapor deposition (CVD) has been widely used for hydrophobization of cellulose aerogels. ${ }^{100-106}$ For instance, Cervin et al. ${ }^{100}$ fabricated highly porous $(>99 \%)$ NFC aerogels with low density $\left(4-14 \mathrm{mg} \mathrm{cm}^{-3}\right)$ and high specific surface area (11-42 $\mathrm{m}^{2} \mathrm{~g}^{-1}$ ) by freeze-drying aqueous dispersions of NFCs. The density and pore size distribution of the aerogels can be tuned by the solid content of nanofibrils in the NFC dispersions. After vapor phase deposition of octyltrichlorosilane (OTS), the NFC aerogels became highly hydrophobic with a water contact angle of $150^{\circ}$. The hydrophobic 
aerogel could selectively absorb hexadecane from water, with an absorption capacity up to 45 times its own weight.

To further improve the oil absorbency of cellulose aerogels, Jiang et al. ${ }^{101}$ successfully fabricated ultralight $(1.7-8.1 \mathrm{mg}$ $\mathrm{cm}^{-3}$ ) and ultraporous (99.5-99.9\%) aerogels from rice straw cellulose. Modification with triethoxy(octyl)silane (OTES) via CVD turned the amphiphilic aerogels more hydrophobic and oleophilic. The silane-modified aerogel can absorb oils or organic solvents up to 139-356 times its own weight depending on the density of the liquids, superior to the absorbents derived from natural organic, inorganic or synthetic polymers. Moreover, the absorbed liquids could be recovered by distillation. However, the oil absorption capacity decreased obviously upon cyclic absorption and distillation. In view of the tedious procedures of oil recovery from cellulose aerogels (e.g., solvent extraction and distillation), Wang et al. ${ }^{103}$ produced highly porous, elastic and recyclable NFC sponges from commercial hardwood pulps via simple microfibrillation treatment, freezedrying and subsequent CVD treatment. The resulting NFC sponges showed an ultra-high absorption capacity of $88-228 \mathrm{~g}$ $\mathrm{g}^{-1}$ for various organic solvents and oils. Owing to the excellent elasticity of the sponges, the absorbed oil could be readily recovered by simple mechanical squeezing. The absorbents could be reused for at least 30 cycles while still retaining high oil absorption capacity ( $137 \mathrm{~g} \mathrm{~g}^{-1}$ for pump oil). In addition to the CVD method, the atomic layer deposition (ALD) technique has also been used for functionalizing the native NFC aerogels with a nanoscale layer of titanium dioxide $\left(\mathrm{TiO}_{2}\right)$ to create a hydrophobic but oleophilic coating, resulting in an oil absorption capacity of $20-40 \mathrm{~g} \mathrm{~g}^{-1} \cdot{ }^{107}$ Although gas phase deposition of hydrophobic coatings is easy to implement and can preserve the high porosity of cellulose aerogels, the grafting distribution of hydrophobic groups within the material is usually not homogenous, with a higher content on the surface. Moreover, aerogel preparation and hydrophobic modification are conducted in separate steps, which is a drawback for practical application.

An alternative strategy is to modify the NFC dispersions prior to the freeze or supercritical drying process. ${ }^{108-112}$ In this way, the entire cellulose aerogel could be functionalized. For instance, Zhang et al. ${ }^{108}$ reported a facile process to prepare hydrophobic, flexible, and low-density $\left(\leq 17.3 \mathrm{mg} \mathrm{cm}^{-3}\right)$ cellulose aerogels by freeze-drying aqueous NFC suspensions with methyltrimethoxysilane (MTMS) as a silylating agent. Due to the growth of polysiloxane layers on the NFC surface, the silylated cellulose sponges displayed good flexibility with a high shape recovery upon compression. The sponges showed good oil/ water selectivity and high absorption capacities (up to $102 \mathrm{~g} \mathrm{~g} \mathrm{~g}^{-1}$ ) toward various organic solvents and oils. The hydrophobic sponges maintained their shape and oil absorption capacity after cyclic extraction/absorption, demonstrating their reusability. Inspired by the chemistry of mussel adhesives, Gao et al. ${ }^{109}$ developed a facile and novel method to fabricate low-density $\left(6.04 \mathrm{mg} \mathrm{cm}^{-3}\right)$, superhydrophobic NFC aerogels by dipping NFCs into a dopamine/octadecylamine (ODA) emulsion, followed by freeze-drying. Here, polydopamine (PDA) was coated onto the NFC by its adhesive properties and the ODA was then attached to the PDA by a Schiff base reaction (Fig. 4).
The PDA interlayer worked as a mediator to bridge the hydrophilic NFCs and the hydrophobic ODA molecules, thus endowing the NFC surface with hydrophobicity. The modified aerogels showed high oil/water absorption selectivity and could absorb a wide range of organic solvents and oils, with a maximum absorption capacity up to $176 \mathrm{~g} \mathrm{~g}^{-1}$. This novel method allows full contact between the NFC scaffolds and the modifier, leading to a uniform structure of the composite aerogels. Recently, Jiang et al. ${ }^{110}$ reported a new approach to fabricate NFC aerogels with multiple improved properties by cross-linking NFCs via their surface hydroxyls with rigid, hydrophobic diisocyanate. The resultant NFC aerogels showed greatly improved compressive properties and thermal stability. Cross-linking also made the amphiphilic NFC aerogels highly hydrophobic, capable of completely separating chloroform from water via simple filtration. These cross-linked cellulose aerogels may allow for continuous separation of oils and hydrophobic liquids from water.

Wood provides a naturally-occurring hierarchical scaffold that can be functionalized at the nano- and microscale and have the strong advantage to be easily scalable for technical applications. ${ }^{95}$ Recently, natural and delignified wood materials have been demonstrated as promising oil absorbents or filtration membranes for oil/water separation., ${ }^{4,113,114}$ Inspired by the tubular porosity and hierarchical structure of wood, Fu et al. ${ }^{4}$ developed strong, mesoporous, and hydrophobic wood/epoxy composites for oil/water separation. Delignified wood scaffolds with high porosity were first prepared by removal of the lignin in bulk wood while retaining its overall morphology and cellular structure. In a second step, the delignified wood scaffold was impregnated with epoxy to reinforce the structure and simultaneously render it hydrophobic. Such delignified wood/ epoxy composites showed good selectivity in oil/water separation and had an oil absorption capacity of up to $15 \mathrm{~g} \mathrm{~g}^{-1}$. Nevertheless, the hierarchically porous structure of wood still holds great potential to be optimized for developing efficient oil absorbents. In a recent study, Guan et al. ${ }^{113}$ reported a novel topdown approach to fabricate highly porous, flexible, and hydrophobic wood sponges from natural balsa wood by selective removal of lignin and hemicelluloses, followed by freeze-drying and a subsequent silylation treatment via CVD. The resultant wood sponges possessed a unique spring-like lamellar structure with wave-like stacked layers, and exhibited high mechanical compressibility and flexibility. The hydrophobic wood sponges can selectively absorb oils on water surface and also under water, with an oil-absorption capacity of up to $41 \mathrm{~g} \mathrm{~g}^{-1}$ (Fig. 5), which is comparable to or better than many reported absorbents.

Moreover, the absorbed oils can be easily collected from the wood sponges by mechanical squeezing and the sponge can endure multiple cycles of absorption and squeezing while retaining the high oil-absorption capacity. Compared with many existing oil recovery methods (e.g., distillation and solvent extraction), mechanical squeezing is more facile to recover oil from the viewpoint of practical applications. ${ }^{96}$ For a continuous separation of oil from the water surface, wood sponges could be built into oil-collecting devices. 


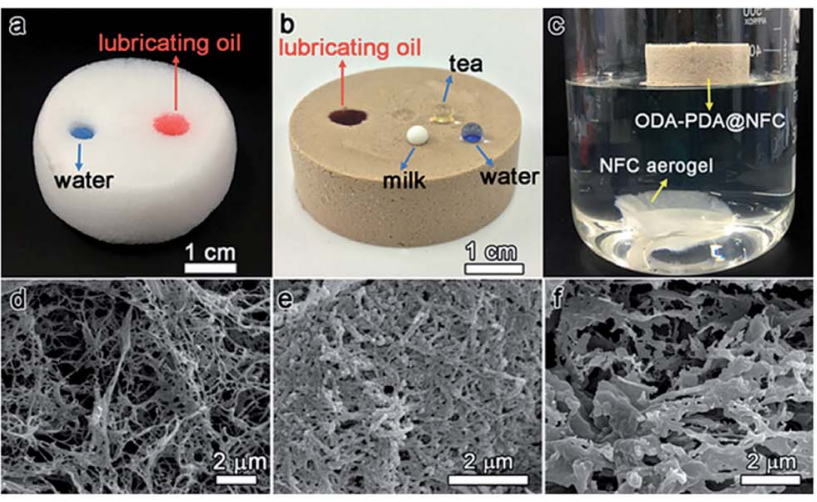

(g)

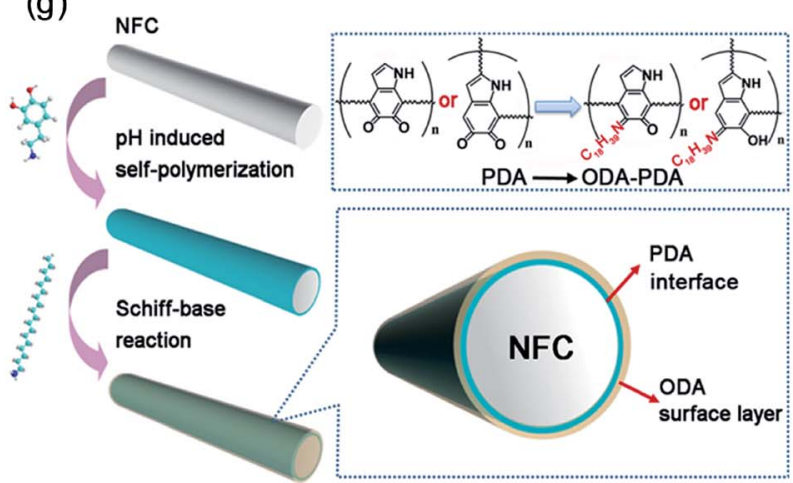

Fig. 4 Behavior of NFC (a) and ODA-PDA@NFC aerogels (b) toward different liquids and in bulk water (c). SEM images of NFC (d), PDA@NFC (e), and ODA-PDA@NFC aerogels (f). (g) Schematic illustration of the fabrication mechanism of the mussel adhesive-inspired, superhydrophobic NFC-based aerogels. Reprinted with permission from the American Chemical Society. ${ }^{109}$

Apart from absorption using absorbents, filtration is another option for oil/water separation. Filtration materials allow only oil or water to penetrate, while preventing the other phase from passing through, resulting in a selective separation. ${ }^{85}$ Recently, Vidiella del Blanco et al. ${ }^{114}$ demonstrated the utilization of native spruce wood cross sections as filter membranes for oil/ water separation. The hydrophilic nature of wood renders it underwater superoleophobic, and the anisotropic porous structure of the wood scaffold directs fluid transport. Such wood membranes can separate water from oil with high efficiency (>99\%). This wood scaffold allows only water to pass through, thus avoiding the adhesion of viscous oils to the filtration scaffold to impair its permeability. These examples of recent research works demonstrate the feasibility of exploiting the natural wood scaffold for oil/water separation.

Besides organic contaminants, water pollution by heavy metals (e.g., cadmium, chromium, lead and mercury) has also become a serious issue and remains a topic of global concern.
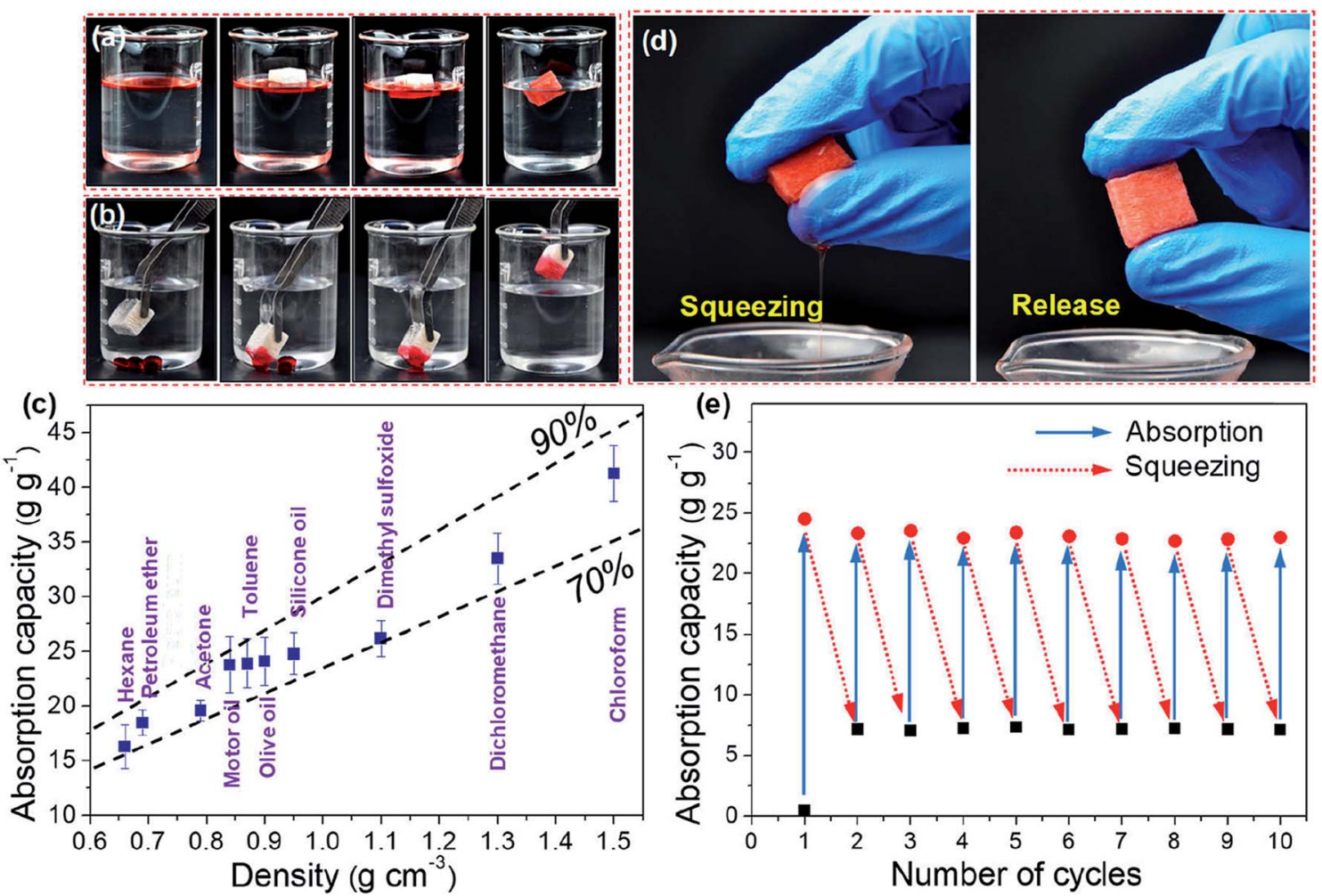

Fig. 5 Oil absorption performance of the silylated wood sponge (SWS). Removal of (a) silicone oil on the water surface and (b) dichloromethane from the water bottom with the SWS. (c) Mass-based absorption capacities of the SWS for various oils and organic solvents. The two dashed lines represent the theoretical volume-based absorption capacity $(\mathrm{v} / \mathrm{v})$ corresponding to the case where the sample is nominally $90 \%$ or $70 \%$ filled with the oils or organic liquids. (d) Photographs showing recovery of silicone oil from the SWS by finger squeezing. (e) Cyclic absorption capacities of the SWS for silicone oil. Reprinted with permission from the American Chemical Society. ${ }^{113}$ 


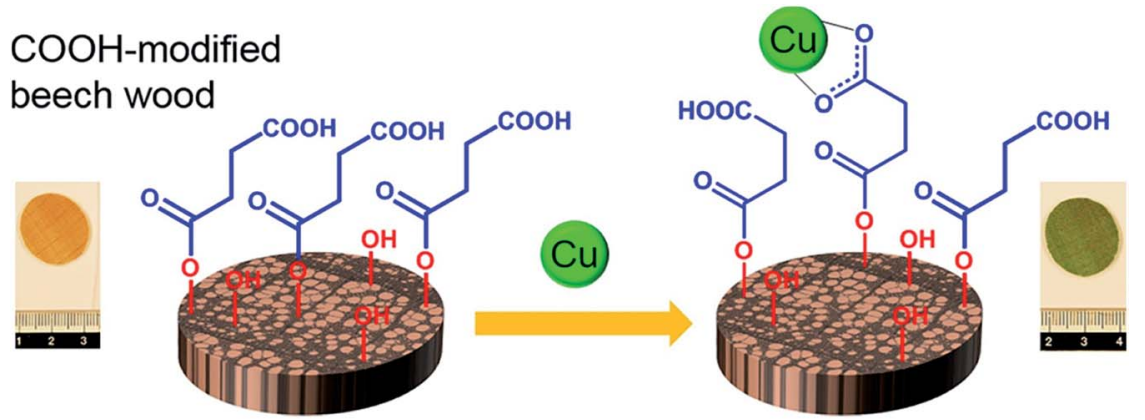

Fig. 6 Schematic diagram of $\mathrm{COOH}$-modified beech wood acting as a bio-adsorbent for the remediation of copper from water. Reproduced by permission of Elsevier. ${ }^{76}$

Cellulose nanomaterials have emerged as a new generation of bio-adsorbent with promising potential application in heavy metal remediation due to their high specific surface area, low cost, sustainability, and broad possibility of surface functionalization. The natural cellulose materials mainly offer hydroxyl groups as reactive or binding sites, and are therefore not able to form stable coordination complexes with metal ions. In order to improve the affinity of the cellulose materials towards heavy metals, surface functionalization is essential to introduce binding sites on the surface of the cellulose for the chelation of metallic species. Carboxylation of cellulose nanomaterials by introducing carboxylic groups is a prevalent strategy for increasing the adsorption capacity of cellulose for heavy metals. ${ }^{115}$ TEMPO-mediated oxidation has proven to be a facile functionalization route to introduce carboxylate groups onto the surface of cellulose nanofibers, resulting in an enhanced adsorption of $\mathrm{Cu}^{2+}$ and $\mathrm{UO}_{2}{ }^{2+} \cdot{ }^{116,117}$ To further enhance the adsorption capacity for heavy metal ions, surface modification of nanocelluloses using carboxylic anhydrides including maleic anhydride, ethylenediaminetetraacetic acid (EDTA) dianhydride and succinic anhydride has also been conducted. ${ }^{118-121}$ For example, succinic anhydride modified nanocellulose was found to effectively adsorb a wide range of divalent metal ions (e.g., $\mathrm{Zn}^{2+}, \mathrm{Ni}^{2+}, \mathrm{Cu}^{2+}, \mathrm{Co}^{2+}$ and $\left.\mathrm{Cd}^{2+}\right)$ from aqueous solutions, and the adsorbent could be regenerated by acid washing and ultrasonic treatment. ${ }^{120}$ In addition to carboxylic groups, other functional groups including amine, thiol and phosphate groups have also been incorporated onto the surface of nanocelluloses, offering active binding sites for heavy metal adsorption. ${ }^{122-124} \mathrm{In}$ general, the functionalized nanocellulose systems with metalbinding groups represent a promising candidates for the removal of heavy metals from contaminated water.

As opposed to the nanocelluloses extracted from plant cell walls, the highly porous and hierarchical wood scaffold itself is also a potential material of choice for the development of a bioadsorbent for heavy metal remediation. Wood cell wall components (i.e., cellulose, hemicelluloses and lignin) possess abundant hydroxyl groups that have the potential to be further functionalized to introduce metal-binding sites. Recently, Vitas et al. $^{76}$ developed a carboxylic groups (- $\left.\mathrm{COOH}\right)$-modified beech wood as a bio-adsorbent for the remediation of copper from water (Fig. 6). The $\mathrm{COOH}$-modified wood was prepared by esterification with anhydrides with a homogeneous distribution of $-\mathrm{COOH}$ groups throughout the wood cell walls. The wood sorbent could remove up to $95 \%$ of copper from low concentration solutions. However, the adsorption capacity of the modified beech wood was found to be limited due to poor accessibility of the $-\mathrm{COOH}$ groups located deep inside the wood cell walls. This exploratory work demonstrates the potential of using the natural wood modified with an appropriate functionality to become a competitive bio-adsorbent or filter for heavy metal remediation.

\section{Conclusion}

In this review we have compared NFC based composites produced in a bottom-up process and wood or cellulose scaffold materials processed in a top-down approach. We have chosen three different categories of properties, in which we studied preparation processes and performances. The comparison shows that the assessment of potentials and limitations strongly depends on the respective field. In terms of mechanical properties, one can clearly see the benefit of remaining the fibre directionality of the hierarchical wood structure. Moreover, densification treatments can be used to reach high fibre volume fractions, which are not easily achieved in assembly processes. Hence, for high-strength performance materials the top-down approach seems to be the more promising alternative. However, by using bottom-up upscaling possibilities like shown for 3D-printing of cellulose nanocrystals ${ }^{125}$ or by cellulose macrofibre spinning in microfluidic devises, ${ }^{2}$ one can uncouple from the structure-determining natural scaffold and achieve strong composites with a higher structural flexibility.

The assembly process of NFC materials and the large surface area of the individual cellulose fibrils facilitate the implementation of additional features like electric or magnetic properties. This is an advantage over wood and wood derived cellulose scaffolds, for which in most cases only a lower degree of functionalization could be achieved due to the complex structure with lower porosity. More research activities are required to find specific functionalization treatments and better understand transport pathways for cellulose scaffolds, in order to fully exploit their potential for functional cellulose materials.

Although NFC-based aerogels have shown promising results as oil absorbents with respect to their high absorption capacity, 
the complicated bottom-up fabrication procedure of cellulose aerogels and the tedious process of oil recovery (e.g., solvent extraction and distillation) are still obstacles to their scalable application. Up to now, most of the NFC aerogel-based oil absorbents are developed for separating immiscible oil/water mixture, and more research attention should be paid to the stable oil/water emulsions, which are more difficult to separate. Wood and cellulose scaffolds have emerged as promising bioadsorbents or filtration membranes for oil/water separation and heavy metal remediation. In contrast with the NFC aerogels produced by the bottom-up approach, the natural hierarchical wood scaffold already provides an intrinsic solution to the upscaling issue.

We summarize that the use of wood and wood derived cellulose scaffolds, which has attracted increasing attention, is a very promising alternative to the assembly of NFC for materials design. Depending on the targeted utilization, either bottom-up or top-down approach can be chosen to develop green and scalable functional materials with high functionality. However, the research on sustainable high performance materials is still at an exploratory stage and needs further advancement.

\section{Conflicts of interest}

There are no conflicts of interest to declare.

\section{References}

1 S. J. Eichhorn, A. Dufresne, M. Aranguren, N. E. Marcovich, J. R. Capadona, S. J. Rowan, C. Weder, W. Thielemans, M. Roman, S. Renneckar, W. Gindl, S. Veigel, J. Keckes, H. Yano, K. Abe, M. Nogi, A. N. Nakagaito, A. Mangalam, J. Simonsen, A. S. Benight, A. Bismarck, L. A. Berglund and T. Peijs, J. Mater. Sci., 2010, 45, 1-33.

2 N. Mittal, F. Ansari, V. K. Gowda, C. Brouzet, P. Chen, P. T. Larsson, S. V. Roth, F. Lundell, L. Wagberg, N. A. Kotov and L. D. Soderberg, ACS Nano, 2018, 12, 6378-6388.

3 M. Frey, D. Widner, J. S. Segmehl, K. Casdorff, T. Keplinger and I. Burgert, ACS Appl. Mater. Interfaces, 2018, 10, 50305037.

4 Q. L. Fu, F. Ansari, Q. Zhou and L. A. Berglund, ACS Nano, 2018, 12, 2222-2230.

5 J. W. Song, C. J. Chen, S. Z. Zhu, M. W. Zhu, J. Q. Dai, U. Ray, Y. J. Li, Y. D. Kuang, Y. F. Li, N. Quispe, Y. G. Yao, A. Gong, U. H. Leiste, H. A. Bruck, J. Y. Zhu, A. Vellore, H. Li, M. L. Minus, Z. Jia, A. Martini, T. Li and L. B. Hu, Nature, 2018, 554, 224-228.

6 H. Yano, J. Mater. Sci. Lett., 2001, 20, 1127-1129.

7 M. Jonoobi, R. Oladi, Y. Davoudpour, K. Oksman, A. Dufresne, Y. Hamzeh and R. Davoodi, Cellulose, 2015, 22, 935-969.

8 H. Kargarzadeh, M. Mariano, J. Huang, N. Lin, I. Ahmad, A. Dufresne and S. Thomas, Polymer, 2017, 132, 368-393.

9 K. Y. Lee, Y. Aitomaki, L. A. Berglund, K. Oksman and A. Bismarck, Compos. Sci. Technol., 2014, 105, 15-27.
10 A. Dufresne, D. Dupeyre and M. R. Vignon, J. Appl. Polym. Sci., 2000, 76, 2080-2092.

11 J. Lucenius, K. Parikka and M. Osterberg, React. Funct. Polym., 2014, 85, 167-174.

12 J. S. Stevanic, E. M. Bergstrom, P. Gatenholm, L. Berglund and L. Salmen, J. Mater. Sci., 2012, 47, 6724-6732.

13 E. Trovatti, H. Tang, A. Hajian, Q. J. Meng, A. Gandini, L. A. Berglund and Q. Zhou, Carbohydr. Polym., 2018, 181, 256-263.

14 T. Zimmermann, E. Pohler and T. Geiger, Adv. Eng. Mater., 2004, 6, 754-761.

15 M. S. Toivonen, S. Kurki-Suonio, F. H. Schacher, S. Hietala, O. J. Rojas and O. Ikkala, Biomacromolecules, 2015, 16, 1062-1071.

16 A. N. Nakagaito and H. Yano, Appl. Phys. A: Mater. Sci. Process., 2005, 80, 155-159.

17 M. Henriksson and L. A. Berglund, J. Appl. Polym. Sci., 2007, 106, 2817-2824.

18 S. Fink, Holzforschung, 1992, 46, 403-408.

19 A. S. Deshpande, I. Burgert and O. Paris, Small, 2006, 2, 994-998.

20 M. I. Shams, H. Yano and K. Endou, J. Wood Sci., 2005, 51, 234-238.

21 J. W. Song, C. J. Chen, Z. Yang, Y. D. Kuang, T. Li, Y. J. Li, H. Huang, I. Kierzewski, B. Y. Liu, S. M. He, T. T. Gao, S. U. Yuruker, A. Gong, B. Yang and L. B. Hu, ACS Nano, 2018, 12, 140-147.

22 Y. Y. Li, Q. L. Fu, S. Yu, M. Yan and L. Berglund, Biomacromolecules, 2016, 17, 1358-1364.

23 M. W. Zhu, J. W. Song, T. Li, A. Gong, Y. B. Wang, J. Q. Dai, Y. G. Yao, W. Luo, D. Henderson and L. B. Hu, Adv. Mater., 2016, 28, 5181-5187.

24 Y. Y. Li, E. Vasileva, I. Sychugov, S. Popov and L. Berglund, Adv. Opt. Mater., 2018, 6, 14.

25 M. Jonoobi, J. Harun, A. P. Mathew, M. Z. B. Hussein and K. Oksman, Cellulose, 2010, 17, 299-307.

26 M. Jonoobi, A. Khazaeian, P. M. Tahir, S. S. Azry and K. Oksman, Cellulose, 2011, 18, 1085-1095.

27 I. Shams, H. Yano and K. Endou, J. Wood Sci., 2004, 50, 337342.

28 H. Fukuzumi, T. Saito and A. Isogai, Carbohydr. Polym., 2013, 93, 172-177.

29 G. Josefsson, B. S. Tanem, Y. J. Li, P. E. Vullum and E. K. Gamstedt, Cellulose, 2013, 20, 761-770.

30 Z. J. Shi, G. O. Phillips and G. Yang, Nanoscale, 2013, 5, 3194-3201.

31 M. Kaushik and A. Moores, Green Chem., 2016, 18, 622-637.

32 C. R. Correa and A. Kruse, Materials, 2018, 11, 1568.

33 E. Kontturi, P. Laaksonen, M. B. Linder, Nonappa, A. H. Groschel, O. J. Rojas and O. Ikkala, Adv. Mater., 2018, 30, 1703779.

34 C. X. Zhan, G. Q. Yu, Y. Lu, L. Y. Wang, E. Wujcik and S. Y. Wei, J. Mater. Chem. C, 2017, 5, 1569-1585.

35 M. Paakko, J. Vapaavuori, R. Silvennoinen, H. Kosonen, M. Ankerfors, T. Lindstrom, L. A. Berglund and O. Ikkala, Soft Matter, 2008, 4, 2492-2499. 
36 C. Sasso, E. Zeno, M. Petit-Conil, D. Chaussy, M. N. Belgacem, S. Tapin-Lingua and D. Beneventi, Macromol. Mater. Eng., 2010, 295, 934-941.

37 C. Y. Ding, X. R. Qian, G. Yu and X. H. An, Cellulose, 2010, 17, 1067-1077.

38 N. D. Luong, J. T. Korhonen, A. J. Soininen, J. Ruokolainen, L. S. Johansson and J. Seppala, Eur. Polym. J., 2013, 49, 335344.

39 G. Mittal, V. Dhand, K. Y. Rhee, S. J. Park and W. R. Lee, J. Ind. Eng. Chem., 2015, 21, 11-25.

40 M. M. Hamedi, A. Hajian, A. B. Fall, K. Hakansson, M. Salajkova, F. Lundell, L. Wagberg and L. A. Berglund, ACS Nano, 2014, 8, 2467-2476.

41 C. Basavaraja, E. A. Jo, B. S. Kim and D. S. Huh, Polym. Compos., 2011, 32, 438-444.

42 N. D. Luong, N. Pahimanolis, U. Hippi, J. T. Korhonen, J. Ruokolainen, L. S. Johansson, J. D. Nam and J. Seppala, J. Mater. Chem., 2011, 21, 13991-13998.

43 A. Kafy, A. Akther, L. D. Zhai, H. C. Kim and J. Kim, Synth. Met., 2017, 223, 94-100.

44 D. Zabetakis, M. Dinderman and P. Schoen, Adv. Mater., 2005, 17, 734-738.

45 Y. Aoki, J. G. Huang and T. Kunitake, J. Mater. Chem., 2006, 16, 292-297.

46 J. S. Jur, W. J. Sweet, C. J. Oldham and G. N. Parsons, Adv. Funct. Mater., 2011, 21, 1993-2002.

47 U. M. Garusinghe, V. S. Raghuwanshi, W. Batchelor and G. Garnier, Sci. Rep., 2018, 8, 2306.

48 G. Kaur, R. Adhikari, P. Cass, M. Bown and P. Gunatillake, RSC Adv., 2015, 5, 37553-37567.

$49 \mathrm{~J}$. Edberg, O. Inganas, I. Engquist and M. Berggren, J. Mater. Chem. A, 2018, 6, 145-152.

50 M. M. Perez-Madrigal, M. G. Edo and C. Aleman, Green Chem., 2016, 18, 5930-5956.

51 Y. Y. Li, H. L. Zhu, Y. B. Wang, U. Ray, S. Z. Zhu, J. Q. Dai, C. J. Chen, K. Fu, S. H. Jang, D. Henderson, T. Li and L. B. Hu, Small Methods, 2017, 1, 1700222.

52 H. Golmohammadi, E. Morales-Narvaez, T. Naghdi and A. Merkoci, Chem. Mater., 2017, 29, 5426-5446.

53 S. Trey, S. Jafarzadeh and M. Johansson, ACS Appl. Mater. Interfaces, 2012, 4, 1760-1769.

54 S. Y. Lv, F. Fu, S. Q. Wang, J. D. Huang and L. Hu, RSC Adv., 2015, 5, 2813-2818.

55 C. J. Chen, Y. Zhang, Y. J. Li, J. Q. Dai, J. W. Song, Y. G. Yao, Y. H. Gong, I. Kierzewski, J. Xie and L. B. Hu, Energy Environ. Sci., 2017, 10, 538-545.

56 J. Y. Wan, J. W. Song, Z. Yang, D. Kirsch, C. Jia, R. Xu, J. Q. Dai, M. W. Zhu, L. S. Xu, C. J. Chen, Y. B. Wang, Y. L. Wang, E. Hitz, S. D. Lacey, Y. F. Li, B. Yang and L. B. Hu, Adv. Mater., 2017, 29, 1703331.

57 H. Z. Guo, M. Buchel, X. Li, A. Wackerlin, Q. Chen and I. Burgert, J. R. Soc., Interface, 2018, 15, 20170864.

58 I. S. Bayer, D. Fragouli, A. Attanasio, B. Sorce, G. Bertoni, R. Brescia, R. Di Corato, T. Pellegrino, M. Kalyva, S. Sabella, P. P. Pompa, R. Cingolani and A. Athanassiou, ACS Appl. Mater. Interfaces, 2011, 3, 4024-4031.
59 R. H. Marchessault, P. Rioux and L. Raymond, Polymer, 1992, 33, 4024-4028.

60 J. A. Carrazana Garcia, M. A. Lopez Quintela and J. Rivas Rey, Colloids Surf., A, 1997, 121, 61-66.

61 A. C. Small and J. H. Johnston, J. Colloid Interface Sci., 2009, 331, 122-126.

62 S. Zakaria, B. H. Ong, S. H. Ahmad, M. Abdullah and T. Yamauchi, Mater. Chem. Phys., 2005, 89, 216-220.

63 Y. Y. Li, H. L. Zhu, H. B. Gu, H. Q. Dai, Z. Q. Fang, N. J. Weadock, Z. H. Guo and L. B. Hu, J. Mater. Chem. A, 2013, 1, 15278-15283.

64 R. T. Olsson, M. Samir, G. Salazar-Alvarez, L. Belova, V. Strom, L. A. Berglund, O. Ikkala, J. Nogues and U. W. Gedde, Nat. Nanotechnol., 2010, 5, 584-588.

65 T. Nypelo, C. Rodriguez-Abreu, J. Rivas, M. D. Dickey and O. J. Rojas, Cellulose, 2014, 21, 2557-2566.

66 W. B. Wu, Y. Jing, M. R. Gong, X. F. Zhou and H. Q. Dai, BioResources, 2011, 6, 3396-3409.

67 S. Vitta, M. Drillon and A. Derory, J. Appl. Phys., 2010, 108, 053905.

68 S. Zakaria, B. H. Ong and T. G. M. van de Ven, Colloids Surf., A, 2004, 251, 1-4.

69 S. Zakaria, B. H. Ong and T. G. M. van de Ven, Colloids Surf., A, 2004, 251, 31-36.

70 Y. Dzenis, Science, 2008, 319, 419-420.

71 T. Prozorov, R. Prozorov and A. Gedanken, Adv. Mater., 1998, 10, 1529-1532.

72 R. Massart, IEEE Trans. Magn., 1981, 17, 1247-1248.

73 C. Katepetch and R. Rujiravanit, Carbohydr. Polym., 2011, 86, 162-170.

74 S. Galland, R. L. Andersson, M. Salajkova, V. Strom, R. T. Olsson and L. A. Berglund, J. Mater. Chem. C, 2013, 1, 7963-7972.

75 M. Bilal, J. A. Shah, T. Ashfaq, S. M. H. Gardazi, A. A. Tahir, A. Pervez, H. Haroon and Q. Mahmood, J. Hazard. Mater., 2013, 263, 322-333.

76 S. Vitas, T. Keplinger, N. Reichholf, R. Figi and E. Cabane, J. Hazard. Mater., 2018, 355, 119-127.

77 X. T. Sun, L. R. Yang, Q. Li, J. M. Zhao, X. P. Li, X. Q. Wang and H. Z. Liu, Chem. Eng. J., 2014, 241, 175-183.

78 H. Oka and H. Fujita, IEEE Trans. Magn., 1999, 35, 35203522.

79 H. Oka, H. Hamano and S. Chiba, J. Magn. Magn. Mater., 2004, 272, E1693-E1694.

80 H. Oka, A. Hojo, K. Seki and T. Takashiba, J. Magn. Magn. Mater., 2002, 239, 617-619.

81 W. T. Gan, L. K. Gao, S. L. Xiao, R. N. Gao, W. B. Zhang, J. Li and X. X. Zhan, Adv. Mater. Interfaces, 2017, 4, 1700777.

82 W. T. Gan, Y. Liu, L. K. Gao, X. X. Zhan and J. Li, Polym. Compos., 2017, 38, 1646-1654.

83 V. Merk, M. Chanana, N. Gierlinger, A. M. Hirt and I. Burgert, ACS Appl. Mater. Interfaces, 2014, 6, 9760-9767.

84 J. S. Segmehl, A. Laromaine, T. Keplinger, A. May-Masnou, I. Burgert and A. Roig, J. Mater. Chem. C, 2018, 6, 3395-3402. 85 Q. L. Ma, H. F. Cheng, A. G. Fane, R. Wang and H. Zhang, Small, 2016, 12, 2186-2202.

86 L. Li, J. Zhang and A. Wang, Chem. Rec., 2018, 18, 118-136. 
87 X. F. Wang, J. Y. Yu, G. Sun and B. Ding, Mater. Today, 2016, 19, 403-414.

88 W. F. Zhang, N. Liu, Y. Z. Cao, X. Lin, Y. N. Liu and L. Feng, Adv. Mater. Interfaces, 2017, 4, 1700029.

89 C. P. Ruan, K. L. Ai, X. B. Li and L. H. Lu, Angew. Chem., Int. Ed., 2014, 53, 5556-5560.

90 Q. Zhu, Y. Chu, Z. K. Wang, N. Chen, L. Lin, F. T. Liu and Q. M. Pan, J. Mater. Chem. A, 2013, 1, 5386-5393.

91 X. C. Gui, J. Q. Wei, K. L. Wang, A. Y. Cao, H. W. Zhu, Y. Jia, Q. K. Shu and D. H. Wu, Adv. Mater., 2010, 22, 617-621.

92 H. Y. Sun, Z. Xu and C. Gao, Adv. Mater., 2013, 25, 25542560.

93 H. C. Bi, K. B. Yin, X. Xie, Y. L. Zhou, N. Wan, F. Xu, F. Banhart, L. T. Sun and R. S. Ruoff, Adv. Mater., 2012, 24, 5124-5129.

94 Y. Zhao, C. G. Hu, Y. Hu, H. H. Cheng, G. Q. Shi and L. T. Qu, Angew. Chem., Int. Ed., 2012, 51, 11371-11375.

95 L. A. Berglund and I. Burgert, Adv. Mater., 2018, 30, 1704285.

96 H. Z. Liu, B. Y. Geng, Y. F. Chen and H. Y. Wang, ACS Sustainable Chem. Eng., 2017, 5, 49-66.

97 N. Lavoine and L. Bergstrom, J. Mater. Chem. A, 2017, 5, 16105-16117.

98 K. J. De France, T. Hoare and E. D. Cranston, Chem. Mater., 2017, 29, 4609-4631.

99 F. Jiang, T. Li, Y. Li, Y. Zhang, A. Gong, J. Dai, E. Hitz, W. Luo and L. Hu, Adv. Mater., 2018, 30, 1703453.

100 N. T. Cervin, C. Aulin, P. T. Larsson and L. Wagberg, Cellulose, 2012, 19, 401-410.

101 F. Jiang and Y. L. Hsieh, J. Mater. Chem. A, 2014, 2, 63376342.

102 C. C. Wan, Y. Lu, Y. Jiao, C. D. Jin, Q. F. Sun and J. Li, J. Appl. Polym. Sci., 2015, 132, 42037.

103 S. Wang, X. W. Peng, L. X. Zhong, J. W. Tan, S. S. Jing, X. F. Cao, W. Chen, C. F. Liu and R. C. Sun, J. Mater. Chem. A, 2015, 3, 8772-8781.

104 S. L. Xiao, R. A. Gao, Y. Lu, J. Li and Q. F. Sun, Carbohydr. Polym., 2015, 119, 202-209.

105 Q. F. Zheng, Z. Y. Cai and S. Q. Gong, J. Mater. Chem. A, 2014, 2, 3110-3118.

106 Y. Jiao, C. Wan, T. Qiang and J. Li, Appl. Phys. A: Mater. Sci. Process., 2016, 122, 686.
107 J. T. Korhonen, M. Kettunen, R. H. A. Ras and O. Ikkala, ACS Appl. Mater. Interfaces, 2011, 3, 1813-1816.

108 Z. Zhang, G. Sebe, D. Rentsch, T. Zimmermann and P. Tingaut, Chem. Mater., 2014, 26, 2659-2668.

109 R. N. Gao, S. L. Xiao, W. T. Gan, Q. Liu, H. Amer, T. Rosenau, J. Li and Y. Lu, ACS Sustainable Chem. Eng., 2018, 6, 9047-9055.

110 F. Jiang and Y. L. Hsieh, ACS Appl. Mater. Interfaces, 2017, 9, 2825-2834.

111 A. Mulyadi, Z. Zhang and Y. L. Deng, ACS Appl. Mater. Interfaces, 2016, 8, 2732-2740.

112 L. K. Lazzari, V. B. Zampieri, M. Zanini, A. J. Zattera and C. Baldasso, Cellulose, 2017, 24, 3421-3431.

113 H. Guan, Z. Cheng and X. Wang, ACS Nano, 2018, 12, 10365-10373.

114 M. V. del Blanco, E. J. Fischer and E. Cabane, Adv. Mater. Interfaces, 2017, 4, 1700584.

115 A. W. Carpenter, C. F. de Lannoy and M. R. Wiesner, Environ. Sci. Technol., 2015, 49, 5277-5287.

116 H. Sehaqui, U. P. de Larraya, P. Liu, N. Pfenninger, A. P. Mathew, T. Zimmermann and P. Tingaut, Cellulose, 2014, 21, 2831-2844.

117 H. Ma, B. S. Hsiao and B. Chu, ACS Macro Lett., 2012, 1, 213-216.

118 Y. Zhou, Q. Jin, X. Hu, Q. Zhang and T. Ma, J. Mater. Sci., 2012, 47, 5019-5029.

119 X. Yu, S. Tong, M. Ge, L. Wu, J. Zuo, C. Cao and W. Song, J. Environ. Sci., 2013, 25, 933-943.

120 S. Hokkanen, E. Repo and M. Sillanpää, Chem. Eng. J., 2013, 223, 40-47.

121 M. d'Halluin, J. Rull-Barrull, G. Bretel, C. Labrugère, E. Le Grognec and F.-X. Felpin, ACS Sustainable Chem. Eng., 2017, 5, 1965-1973.

122 R. Yang, K. B. Aubrecht, H. Ma, R. Wang, R. B. Grubbs, B. S. Hsiao and B. Chu, Polymer, 2014, 55, 1167-1176.

123 S. Hokkanen, E. Repo, T. Suopajärvi, H. Liimatainen, J. Niinimaa and M. Sillanpää, Cellulose, 2014, 21, 14711487.

124 P. Liu, P. F. Borrell, M. Bozic, V. Kokol, K. Oksman and A. P. Mathew, J. Hazard. Mater., 2015, 294, 177-185.

125 G. Siqueira, D. Kokkinis, R. Libanori, M. K. Hausmann, A. S. Gladman, A. Neels, P. Tingaut, T. Zimmermann, J. A. Lewis and A. R. Studart, Adv. Funct. Mater., 2017, 27, 10. 